\title{
THE IMPACT OF BANKING ETHICS ON THE FINANCIAL PERFORMANCE OF BANKS
}

\author{
Khodor SHATILA \\ IProCares International Research Center, Beirut, Lebanon \\ info1@iprocares.com
}

\begin{abstract}
Banking plays a decisive part in civilization in the twenty first century. It enables operations and transactions between persons, businesses, and other institutions in an economy through its functions. The modern banking facilities are a prerequisite to meeting fundamental expectations such as purchasing a house or even earning salaries from employers. A change in the way people deal with money has been inspired by the banking account where people are invited to put their money on a bank account instead of putting it under a mattress. Banks have developed a strong reputation around checking accounts using the protection statement that people are more likely than in a bank to lose their money home. This statement has served to guarantee that the funds are physically protected and stable by taking safety precautions in banks. The research implemented a mixed approach methodology throughout implementing both interviews and questionnaires for collecting data. Any banks do not see and integrate ethics in their whole enterprise as a barrier to their success or activities. The so-called ethical banks are not a single business model since they arise from diverse historical contexts and represent real market conditions. There are banks based on anthroposophy and banks based on a pledge to support societies that have developed them, green banks and banks that combat poverty unbanked by microfinance in emerging economies. All of them place employees first and share ideals of sustainability, openness, tolerance and integration.
\end{abstract}

Keywords: Financial Performance, Banking Ethics, Financial Statements, Ethical Challenges.

DOI: https://doi.org/10.24818/beman/2021.11.4-07

\section{INTRODUCTION}

Banking plays an important part in civilization in the twenty first century. It enables operations and transactions between persons, businesses and other institutions in an economy through its functions. The modern banking facilities are a prerequisite to meeting fundamental expectations such as purchasing a house or even earning salaries from employers. A change in the way people deal with money has been inspired by the banking account where people are invited to put their money on a bank account instead of putting it under a mattress (Chokprajakchat, 2017).

It was not an isolated occurrence since related Bank events happened during the Greek crisis, and there was increasingly outrage among bank customers at demonstrations like Occupy Wall Street or at the annual meetings of the Bank's shareholders (Çelikdemir, 2015). These signs were only indicators of a broader public 
malaise. Banks simply lost popular confidence: an important component of every financial transaction. The banking system is based on confidence and therefore requires confidence to operate efficiently. At a fundamental stage, the bank note is the emblem of the trust in the banking sector, as each note carries the commitment rendered to the holder (Albu, 2020).

In a time where the world was stuck with economic crises, incidents that represented a response from the population were mostly caused, stimulated and encouraged by the combination of several events, processes and shortcomings within the banking sector. The challenges in the US and UK immobilizing sectors and the uncertainties in connection with high leverage in banks caused Lehman Brothers to bankrupt in 2007. In stock markets, this bankruptcy caused mayhem, which sparked fear worldwide. The crash followed the development in the immobilization industry for a long time that resulted in the building sector becoming a bubble. The house price grew into a bubble, which enabled banks to participate in sub-prime lending which was a widely used business activity as a result of the crash and subsequent inquiries. Many of the risky subprime credits approved under regulatory oversight by banks culminated in customer insolvencies and asset repossessions, leading banks to an ever-greater pile of toxic assets affecting liquidity (Dekerckhove, 2017).

Furthermore, in the financial sector, a recent development took place more extensively. The structure of shadow banking, including unregulated financial institutions and unregulated businesses of controlled financial companies, has become increasingly common. By shadow banking activities, companies have also been able to hold off track any of these toxic assets reporting more strongly on equity values than realities and infants according to (Saitri, 2017).

The shadow banking framework also enabled financial institutions to take more risks, particularly among investment banks, with a very high level of leverage. Innovative practices have also been instrumental in the development of the crisis. The creditors followed a "originating to distribute" paradigm with the stock of toxic assets in banks and the growing challenge of liquidity issues.

Contrary to the conventional lending paradigm in which the investor uses its assets and is reimbursed by the borrower over a span of time, the uncertainties lie with the lender who checks thoroughly when the borrower can reimburse. In order to market the contracts to a third entity, either an agency or an investor, in the case of an original distributor, the lender loans capital to the supplier (Ramboarisata, 2019).

These sales, however, would not be likely if the loans bundled and packaged in mortgaged securities were not circulated in a dynamic scheme of derivatives, and the credit rating agencies graded them as secure and AAA classified. If any mortgage-backed securities have been assessed as volatile, they have been AAA classified debt bonds according to (Ali, 2016). 
Consequently these shares have been purchased because of high reviews. But since the credibility of those loans remained doubtful, several investors purchased the securities with another invention, the Credit Default Swaps according to (Abdulkareem, 2017). The credit default swaps have provided an opportunity for buyers to hedge positions and to expose themselves to mortgage-backed securities and collateralized debt obligations according to (Olmos, 2019).

The aim of this research is to identify factors in the environmental set up that influence behaviours in the industry and evaluate the existing methods of prevention. In order to achieve this aim, the following research objectives were formulated:

Objective 1: To analyze the secondary ethics analysis in the banking sector

Objective 2: Ethics in the biggest crisis affecting banking in history can be assessed objectively.

Objective 3: Evaluating the industry's existing climate and identifying causes which could hinder industry ethics.

Objective 4: Evaluation of emerging structures employed to discourage immoral behaviors.

In order to reach the objectives of this study several questions were formulated during this study:

- Question 1: Has the ethical culture in the industry evolved or has it remained the same?

- Question 2: How suitable is the current industrial, political and social set-up to the existence of ethics in banking?

\section{SIGNIFICANCE OF THE RESEARCH}

This study examines the ethical culture of banking in how ethics is promoted in banks, behavioral influencers and regulators. The study aims to examine whether forces within and around the banking sector are able to affect employee behavior and create anomalies with regard to anomaly determinants in the Lebanese banking industry.

This study shows whether or not substantial progress has been made in shaping behavior and maintaining the bank industry a good ethical culture. It also brings the regulatory reaction to the current crisis into context by looking into the regulatory reactions to previous crises; to identify whether sufficient attempts are historically made in the sector to solve ethical problems when regulators enter post-crisis situations; and whether the 2007 recession comparisons with past crises remain. The banking industry has made great advances, especially in its strategies, scope, instruments and operations.

\section{BUSINESS ETHICS STRATEGY IN BANKING}

Ethics is of immense significance to the financial industry as any company appreciates the prestige and success it has built for itself (Dekerckhove, 2017). 
It is claimed that, when ethics is implemented, a bank has respect for fairness, dignity, social conscience, transparency and conformity. In gray areas of ethics and under heavy strain, banks may make decisions that can damage credibility and trigger financial risk. No bank will say that bribes are recognized as acceptable in return for loans, selling to related parties or misleading customers (Geeta, 2016).

The banks also can not exclusively stick to the ethical standards to be established in the sector. The cause of the several confrontational issues in the banking industry is bribery and corruption.

Honesty and transparency in the banking sector are of high importance. The bank's sustainability is decided by trustworthiness. Usually, average citizens would be unable to get an equal understanding and the requisite technological expertise $A$ typical bank customer has little ability and sufficient information to understand how transactions in the banking hall are done.

\section{ETHICS AND THE CONCEPT OF BUSINESS ETHICS}

Asu (2017) called the ethics metaphysical analysis of the appropriate or the wrongdoing of humanity. An agreed theory of good or wrong regulating the conduct of an individual, the activities of representatives of the community, or the acts of an association" says Dana (2017) believed that a large career is willing to assume obligation to behave in the public interest, needing a transparent engagement of its own connection.

Both companies have to raise profits, if they do not, their primary goal has failed. This is in violation of our societal framework that allows and promotes its commercial practices because it performs so in an unethical manner. The aim of teaching ethics is to continually state that company has the purpose of gaining and producing profits with respect. From this, it becomes clear that immoral financial practices with some bank or other company can be detrimental, and is unfair, to the bank, the depositors or other banks and the banking public as a whole.

Because of their critical and significant position as custodian of public and private funds, banks play a function both in financial intermediation; the banking sector transcends income. Therefore, there are growing corporate and technical principles that banks ought to accept to represent them as legal, healthy, secure and trustworthy organizations according to Durr (2019).

Ethics vary from functional concerns established, such as a requirement for a business to be truthful with its clients, to broader social and ethical problems, such as an enterprise's environmental duty and workers' rights. Most legal issues occur out of disputes between the various desires of company leaders and their workers. The management ought to reconcile the ideal with the real - the need to allow fair gains of fairness in corporate operations, health at work and greater environmental and social problems to the owners of the firm. The multinational, diversified existence of many major companies and the 
sophistication of government laws that determine the limits of illegal activity combine render business problems much more complicated according to Hunt (2018).

\section{ROOTS OF UNETHICAL BEHAVIOR AND THE VALUE OF ETHICAL BEHAVIOR}

It is necessary to understand that corporate ethics are not separate from human ethics, the standards of good and wrong behavior that are widely recognized. We as people are told that deception and stealing is immoral is false and that it is honorable or correct to behave with honesty and honor, to protect what we believe is good and true. A variety of outlets, including our community, teachers, faith, and the media, provide the basic framework of professional behavior that controls us. An employee with a good sense of moral ethics is less prone to act unethically in a corporate setting according to Horng (2019).

Although the key goal of ethics is to determine the rightness of an activity rather than to measure how it contributes to greater corporate gain, there have been several attempts to evaluate the financial benefit of ethical behavior and good corporate citizenship. Most qualitative and interpretation research in this area are distinguished by a variety of analytical faults because the financial benefits in corporate ethics are not accurate according to Nugraha (2015).

Despite this, all such studies seem to foster an innate perception of corporate knowledge among entrepreneurs; honesty is the pillar of a viable enterprise and makes an significant contribution to the interest of shareholders. Perception studies indicate that diverse societies, sectors and countries are reliable. There is an increasing belief that ethical businesses, particularly in the long run, would be more effective than those not.

Within this new era, within fact, it is challenging to recognize the importance of business ethics without specific statistics. Nevertheless, case studies in multinational ethnic groups are abundant in the company sector. Recent findings have found that strong governance and corporate ethics practices improve company performance and market growth. Over 200 companies, consumers and executive officers (about one quarter of who are CEOs) were interviewed in 116 nations, each controlled about \$2 trillion of properties according to Geeta (2016).

The first indicate high rates of government, which in Central, Western Europe and Africa, imply premiums of $12-14 \%$. Interestingly enough, the second study revealed that while more than half of all executives operate in public relations and lobby as tactics to address social and political issues, more successful approaches are used to improve commodity or process vulnerability accountability according to Ferrell (2018). 


\section{FAILURE OF BUSINESS ETHICAL STANDARDS IN BANKING INDUSTRY}

The banking business is based on trust which is necessary due to imperfect information by customers' complex transactions and vulnerability. As they operate on risk and profitability, banks will stick to such ethical standards, including fair-mindedness, honesty, social justice, transparency and fairness, in banking and corporate ethics according to Haghighattalaba (2019).

There were numerous adverse effects of these "bad" banks on the economy. The banks had to increase the interest rate charged on private sector deposits and their rivals had to follow suit owing to this pressure on their balance sheet. Codes of corporate practices were developed in many jurisdictions in order to draw up a road-map to curb any of these immoral activities of corporations according to Jamal (2018).

The Sarbanes-Oxley Act 2002 in the States, in reaction to the Enron debacle, is a product of these standards of professional conduct. The scandal also indicted Arthur Andersen, one of Enron's largest accounting firms. In Addition, the SEC of Addition introduced in 2003, for public firms, the Code of Best Practices on Corporate Governance.

\section{INSTITUTIONALIZATION OF ETHICS}

Managers are responsible for creating an organizational atmosphere which increases ethical decisionmaking by institutionalizing them or making them necessary at the workplace, particularly in top decision maker positions.

This includes the implementation of ethical principles of people's everyday lives. This can be achieved in three ways: by the introduction of an appropriate corporate policy or code of ethics; by the usage of a officially appointed ethics committee); and through the creation of awareness and ethics systems for management (Horng, 2019).

A code of conduct, including ethical standards, will be included in the results assessment. In addition, several businesses relate wages and benefits to ethical conduct. Managers will always use the chance to encourage and foster ethical conduct. At the same time workplace disclosing inappropriate behavior will be promoted.

\section{CODE OF ETHICS}

While corporate ethics has evolved, the company sector has expanded in recent years. Ethical standards have been influential in people's organizational practices. Nevertheless, it is therefore necessary to note that the establishment of a code of ethics is not the sole method of meeting an organization's ethical goals. 
Since the code of ethics was the very first method taken by executive executives, the company does not benefit optimally from the collection of rules of behavior if the system is applied and established in a single instrument. The biggest downside is that individuals in an organization may acquire a misjudging and security perception.

It is when individuals in an organization believe like they are prohibited from having their own freedom at work or should determine what is correct and wrong. An organization's code of ethics defines the basic principles and its structure and guarantees consistency with the organization's purpose and vision. It typically specifies the actions of people employed in a company, which offers a belief structure that all representatives of a company ought to act by and that employees will follow in an organization as they interact with stakeholders in the organization. The groups affected can be internally as well as externally. The code of ethics drawn up by an organization is a guide by administrators and workers to work in a company.

It further defines the short- to long-term priorities of an organization through explaining to the outside community the fundamental principles of the company.

The workplace also behaves in a manner that explicitly determines the procedures by which companies function and evaluate all management and other personnel's actions and behaviors. A properly developed code of ethics for an entity will resolve an organization's ethical shortcomings and explains how an organization's actions will be governed. Ethics in an organization have been developed to resolve environmental concerns and also to control how people engage with the company, collaborate, secure goods marketed to consumers, how people give and accept gifts in an organization.

It states what causes, among other issues, conflict of interest and corruption. A variety of issues have to be discussed and a variety of actions have to be made in order for an individual to establish a collection of rules of ethics. (Chokprajakchat, 2017)

This includes the reason for which it is drawn up. In order to produce a successful draft, the company carries out a risk evaluation that defines how the entity progresses from the present state of affairs to the highly anticipated ethical organization.

There is an essential sound of speech for which the codes are published and transmitted and they play a significant role in their efficacy. It can vary from a prohibitive to a constructive one that serves the reason for which it is drawn up. Implementation means that the technology developed is applied in all of the organization's activities and is clear. It is not a moment when it is presented for a spotlight in the context of a writing word. The company must be seen to function under the specified company codes by enforcement (Beinstein, 2019). 


\section{MAKING DECISIONS IN BUSINESS ETHICS}

No structured system is used for ethics. This varies under various situations. In concept, it is abstract. Consequently, no consistent solution should be given to legal problems.

As the idea of ethics is primarily concerned with people, since even human beings have the ability and free will to do so. Two of the consequences were the Ethical 29 ruling attributable to the verdict. Each has a particular point of view. People have different ethical practices as well. Decisions about ethics thus differ between people. Ethical judgments are not universal and can differ from individual to individual.

Decision taking in an organization is a big activity of the business. It is the basis for achieving the goal properly. The business judgment would be legal. Ethical judgments lead to the correct and incorrect choice. However, we have already defined a condition in terms of justice through the vocabulary of right and wrong. There is therefore an essential identifying process which precedes this by evaluating circumstances and deciding whether they are primarily defined by these considerations.

In a business ethics judgment, both the owners and the public will benefit. Numerous factors influence the decision-making process. An ethical judgment is not only confined to them, it also involves a vast variety of certain cases. Similarly, immoral judgments have broad consequences that do not stop in themselves. Ethical choices are collective human acts. An act considered ethical or unethical must therefore be voluntarily the result of people's actions, without being forced into the act.

\section{IDENTIFYING THE POPULATION}

A whole collection of cases or community members shall be identified as a population. This refers to the cumulative number of individuals satisfying the criterion for selecting the study. Given the importance in this report, we concentrate on practitioners that satisfy those requirements.

At the time of data collection, respondents had to be specialists and had to be regarded in commercial banks. These concepts of commercial/retail banks in Lebanon were used to define profiles:

This means that we protect middle management, organizational level and top management. In this study, it is essential to cover all layers.

Top management determines goals and tactics and measures the group's cumulative efficiency. They are capable of determining the parameters workers are compensated and/or disciplined for their conduct, hence their willingness to encourage or prevent activities by enforcing policies according to the group's goals.

In order to reach the deadlines, the middle managers coordinate and monitor their departments. They also evaluate the efforts and behavior of their team's subordinates. This test will also be the foundation 
on which an employee will be rewarded or disciplined. They might still be under strain when it comes to reaching objectives.

Finally, the operational workers adopt the methods and function to accomplish their goals. That is the front line, and it is in communication with consumers.

\section{SAMPLING SIZE}

As articulated above, our total population is 2400 . In order to come up with a suitable sample size, we referred to Krejcie and Morgan and their sample size table. This table indicates that for a population of 2400 , one needs a sample size of 181 people to be $95 \%$ confident. This represents a margin of error of $5 \%$.

\section{DATA COLLECTION}

In order to collect the data, the method used was the internet-mediated survey. The data was collected using Google Forms within a timeframe ranging between 5 February and 28 February.

\section{DESCRIPTIVE STATISTICS FOR ATTITUDES}

TABLE 1. DESCRIPTIVE STATISTICS FOR ATTITUDES Descriptive Statistics

\begin{tabular}{|c|c|c|c|c|c|}
\hline & $\mathrm{N}$ & Minimum & Maximum & Mean & Std. Deviation \\
\hline $\begin{array}{l}\text { For the most part at work, there is no } \\
\text { right or wrong way to achieve the } \\
\text { bank's goals. }\end{array}$ & 181 & 1 & 5 & 3.79 & 1.049 \\
\hline $\begin{array}{l}\text { At work it is considered okay to play } \\
\text { dirty to win }\end{array}$ & 181 & 1 & 5 & 3.87 & .939 \\
\hline $\begin{array}{l}\text { The attitude in our bank is that } \\
\text { sometimes it is necessary to lie to } \\
\text { others in order to keep their trust }\end{array}$ & 181 & 1 & 5 & 3.48 & 1.200 \\
\hline $\begin{array}{l}\text { In our bank, the rules can be broken } \\
\text { in order to achieve banks goals }\end{array}$ & 181 & 1 & 5 & 3.29 & 1.103 \\
\hline $\begin{array}{l}\text { The prevailing attitude in our bank is } \\
\text { that "nice guys finish last." }\end{array}$ & 181 & 1 & 5 & 3.71 & 1.113 \\
\hline $\begin{array}{l}\text { In our bank the feeling is that the } \\
\text { ends justify the means }\end{array}$ & 181 & 1 & 5 & 3.13 & 1.249 \\
\hline $\begin{array}{l}\text { In our bank you have to be willing to } \\
\text { break some rules if that is what it } \\
\text { takes to get the job done }\end{array}$ & 181 & 1 & 5 & 3.45 & 1.077 \\
\hline Valid N (leastwise) & 181 & & & & \\
\hline
\end{tabular}

Source: The Author 
The above table describes the descriptive statistics of attitudes to study the impact of banking ethics on financial performance. The $\mathrm{N}$ represents the sample addressed, as for the minimum and maximum represents the scale used to measure the questionnaire ranging from 1 (Strongly Agree) to 5 (Strongly Disagree), as for the mean it represents the average responses.

It can be noted that most of the respondents replied by neutral regarding the questions related to measure the attitudes of employees in the workplace since the statements related to this variable scored means of $3.79,3.87,3.48,3.29,3.71,3.13$ and 3.45 which falls into the neutral category according to the scale used in our study.

\subsection{DESCRIPTIVE STATISTICS NORMS}

TABLE 2. DESCRIPTIVE STATISTICS FOR NORMS

Descriptive Statistics

\begin{tabular}{|l|c|c|c|c|c|}
\hline & $\mathrm{N}$ & Minimum & Maximum & Mean & Std. Deviation \\
\hline $\begin{array}{l}\text { The bank I currently work at applies an ethical policy } \\
\text { that is clear, that allows all colleagues to identify } \\
\text { ethical situations when they arise, and helps them in } \\
\text { their decision making }\end{array}$ & 181 & 1 & 5 & 3.92 & 1.027 \\
$\begin{array}{l}\text { The ethical decision making process employees } \\
\text { have been prompted to use has often helped me } \\
\text { identify potential ethical issues } \\
\text { Valid N (leastwise) }\end{array}$ & 181 & 1 & 5 & 3.75 & 1.110 \\
\hline
\end{tabular}

Source: The Author

The above table represents the descriptive statistics related to the norms variable, the two statements related to this variable scored a mean of 3.92 and 3.75 which falls into the neutral category according to the scale used in the research.

\subsection{DESCRIPTIVE STATISTICS INTENTION}

TABLE 3. DESCRIPTIVE STATISTICS FOR INTENTION Descriptive Statistics

\begin{tabular}{|l|c|c|c|c|c|}
\hline & N & Minimum & Maximum & Mean & Std. Deviation \\
\hline $\begin{array}{l}\text { Success means posting positive quarterly figures that will } \\
\text { increases share price }\end{array}$ & 181 & 1 & 5 & 3.46 & 1.108 \\
\hline
\end{tabular}




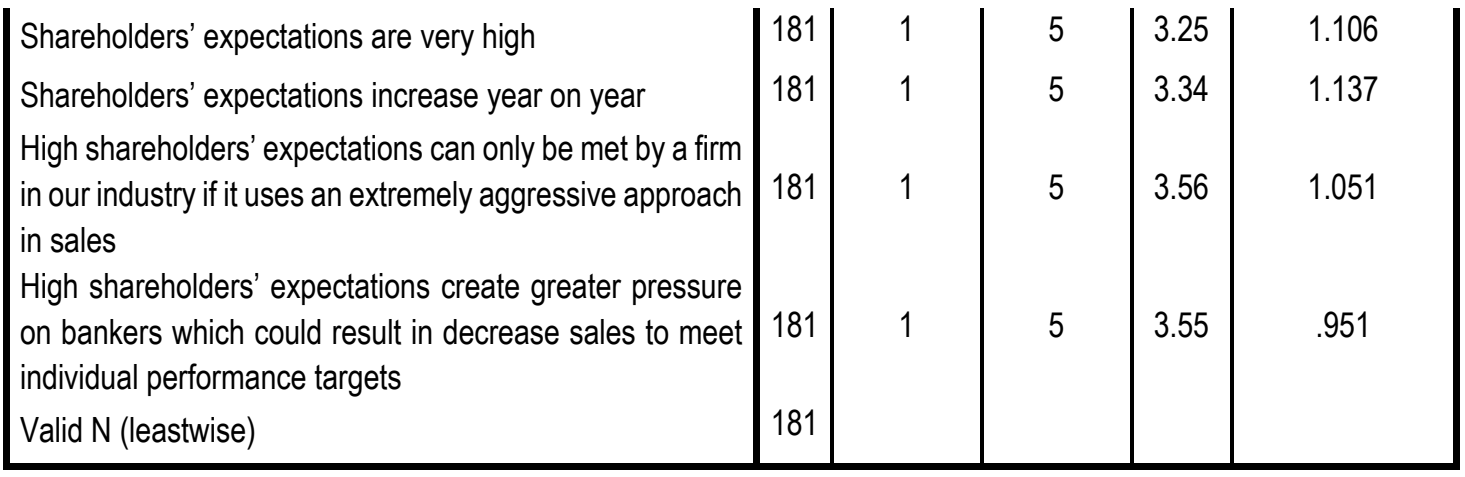

Source: The Author

The above table describes the statements related to the intention variable of the research, and it can be noticed that most of the respondents scored a mean ranging between 3.25 and 3.55 falling into the neutral category according to the used scale.

\section{REGRESSION ANALYSIS}

TABLE 4. REGRESSION ANALYSIS Model Summary

\begin{tabular}{|c|c|c|c|c|}
\hline Model & $\mathrm{R}$ & $\mathrm{R}$ Square & Adjusted R Square & Std. Error of the Estimate \\
\hline 1 & $.870^{\mathrm{a}}$ & .757 & .753 & .01283 \\
\hline
\end{tabular}

a. Predictors: (Constant), Intention, Attitudes, Norms, ROE

\section{Coefficients}

\begin{tabular}{|c|c|c|c|c|c|}
\hline \multirow{2}{*}{ Model } & \multicolumn{2}{|c|}{ Unstandardized Coefficients } & \multirow{2}{*}{$\begin{array}{c}\text { Standardized Coefficients } \\
\text { Beta }\end{array}$} & \multirow{2}{*}{$t$} & \multirow{2}{*}{ Sig. } \\
\hline & $B$ & Std. Error & & & \\
\hline (Constant) & -.005 & .005 & & -.965 & .336 \\
\hline Intention & .162 & .046 & .168 & 3.555 & .002 \\
\hline Attitudes & .580 & .052 & .524 & 11.091 & .001 \\
\hline Norms & .313 & .046 & .328 & 6.831 & .001 \\
\hline
\end{tabular}

a. Dependent Variable: ROE

Source: The Author 
Preference to the mentioned regression analysis, we aim to test whether the hypothesis is rejected or accepted based on a margin error of $5 \%$. If the significance level showed a margin error below than $5 \%$, then the null hypothesis will be rejected and the alternative one will be accepted and vice versa.

It can be noticed from the above table that intention Significance level of (0.002) and a T-Test of 3.55, attitudes scored a significance of (0.001) and a T-Test of 11.091 and norms scored a significance of (0.001) and a T-Test of 6.831. Since all the significance levels are below than 0.05 and the T-Test is above 2, this means that there is a direct relationship between intention, attitudes, norms and ROE, and by that the following can be determined:

Thus, the following regression formula can be determined:

$Y=A+B X 1+B X 2+B X 3$

$Y=$ dependent variable $A=$ constant,$B=$ Betta variations and $X=$ independent variables

$\mathrm{ROE}=-0.05+0.162$ intention +0.580 attitudes +0.313 norms

This can define the following:

- For every one unit increase in intention, the ROE tends to be affected by 0.162 units;

- For every one unit increase in attitudes, the ROE tends to be affected by 0.580 units;

- For every one unit increase in attitudes, the ROE tends to be affected by 0.313 units.

\section{INTERVIEW FINDINGS}

Interview one had been conducted with a bank branch manager in Lebanon, and the findings from the hypothesis test were that strategic aggression, competitive strength and long-term guidance have an important impact on the industry's anomie. Based on these results, the study is aimed at reviewing the ethics standards and codes of conduct in selected banks to examine the current mechanisms structured to discourage immoral behaviors.

In order to determines if instruction in the moral decision making phase was given, the codes of behavior and ethics of the chosen banks were screened. They were also tested in line with the results of the test hypothesis in order to identify clear policies that include employee conditions that regulate or restrict anomaly through variables like strategic aggression, competitive strength and long-term orientation.

Interview Two had been conducted with the HR department in a Lebanese Bank and he stated that banks got more assistance in the code of conduct or code of ethics on decision making, outside the declarations of principles and planned employees' behavior. Which means that support in the form of questions can be asked by staff before a decision is taken. 
Corporate policies enable a culture to be created in a company. Ethical rules, legislation and regulations include a starting base, which enables workers to define and form their obligations in a manner that is compliant. The decision/action of the employees could be strongly influenced in the event of an ethical question, given the applicable law and organization policies. Both banks who have policy guidelines invite staff to at least take this factor into account. In particular, during decision-making banks require their staff to understand legal and business practices.

Interviewee three stated that banks which provide employees with a basis for decision-making shall incorporate into the list of considerations the potential effects of decisions or acts on the banks and shareholders. Any banks are not limited to customers or the bank alone to weigh the implications. But banks want their workers to take into account the impact of their decisions on the firm.

Unlike the impact of the actions on the bank, in their decision-making guidance and collection of factors, both banks do not define the effect of actions on consumers. These banks account with unique implications for consumers. Although they don't discuss customers in particular, the decision-making guidelines often include customers, as the implications are often foreseen for workers without any restriction.

\section{MAIN FINDINGS}

The following table addresses the interviews done with six principles based on principle of sustainable banking, and the following are the results:

TABLE 5. PRINCIPLES OF SUSTAINABLE BANKING

\begin{tabular}{|c|r|c|}
\hline & Principles of Sustainable Banking & Dimensions \\
\hline Principle 1 & Triple bottom line approach at the heart of the business model & F,S,E \\
\hline Principle 2 & $\begin{array}{c}\text { Grounded in communities, serving the real economy and } \\
\text { enabling new business models to meet the needs of both }\end{array}$ & F,S \\
\hline Principle 3 & $\begin{array}{r}\text { Long-term relationships with clients and a direct understanding } \\
\text { of their economic activities and the risks involved }\end{array}$ & F,S \\
\hline Principle 4 & Long-term, self-sustaining, and resilient to outside disruptions & F \\
\hline Principle 5 & Transparent and inclusive governance & G \\
\hline Principle 6 & All of these principles embedded in the culture of the bank & S,G \\
\hline
\end{tabular}

Source: The Author 
Note: Abbreviations for dimensions: F - financial, S - social, E - environmental, G - corporate governance.

Any banks do not see and integrate ethics in their whole enterprise as a barrier to their success or activities. The so-called ethical banks are not a single business model since they arise from diverse historical contexts and represent real market conditions. There are banks based on anthroposophy and banks based on a pledge to support societies that have developed them, green banks and banks that combat poverty unbanked by microfinance in emerging economies. All of them place employees first and share ideals of sustainability, openness, tolerance and integration.

A number of member organizations, normally conditioned by a collection of standards, were formed to link potential leaders in the sector. In order to be used as the main grouping of ethical banks and help to differentiate between them and traditional banks, the six sustainable banking principles synthesized in the GABV are used. While the standards primarily summarize all member banks of the GABV, they may usually be extended in the industry. The Principles and other sustainable systems in economics and finance are often apparently identical.

The conception of universality stipulates that an event does not, where implemented uniformly, negate its maxim such that its outcomes remain consistent with original purposes, whereas the Formula of the End of itself focuses on employees, who must still be the ultimate objective. The two rules are generally used without regard to distance, but if the formulas of universality and civilization are combined and projected in time we get nothing short of the idea of survival.

A sustainable activity may be characterized by the ethical framework as one that does not explicitly or indirectly affect employees, in the society and the period. It must be said that indirect damage may be achieved by developing harmful social environments and waste.

Ethical banks should not have profitability as their prime objective in accordance with the humanity formula. Instead, they are targeted at meeting human interests, including decent environmental standards, and financial sustainability is an integral prerequisite for that. Financial sustainability however does not simply entail optimizing benefit and long-term stability over short-term performance.

Profitability and volatility are very critical, but ethical banks are placing at least the same focus on other financial success metrics that overlap to a certain degree with the corporate social factor. Examples of such steps might be debt loss rates or share of assets exposed to the real economy. 


\section{IMPLICATIONS OF THE STUDY}

Many studies have been conducted in the field of business ethics with the aim to understand the influencers of employee's behavior at work. However most of these studies focused on industries other than the banking industry.

Furthermore none of the studies focused on the factors built in the banking industry in the effort to understand the forces influencing employee behavior. In light of this, the original findings of this research generate a number of implications on banks and on the governments and regulators.

\section{LIMITATION OF THE RESEARCH AND OPPORTUNITIES FOR FUTURE RESEARCH}

The research had to overcome a scarcity of materials in the literature concerning ethics management and governance in the banks. Furthermore some of the factors that were tested as independent variable in this research were not observed in the literature. This forced the development of new subscales.

The researcher had to work around issues related to the data protection policies of the institutes where members were targeted.

The stratified random sampling was based on the number of years of experience of the members as the institutes refused to provide details such as the job titles, contacts and banks where the members worked. However the questionnaire was designed to gather personal information with the consent of the participants.

Furthermore, many difficulties were encountered to have an acceptable response rate. The number of respondents could have been much greater were it not for the sensibility of the topic of ethics.

As participation was voluntary, the participants may by nature have a strong sense which, coupled with the efforts institutes invest into raising awareness regarding the importance of ethics in the banking industry, could make the sample in this study less representative of the reality.

Finally, the research focuses only on bank employees that hold positions with responsibilities directly contributing to the core activities of the firm. Support staffs were not considered in this research despite also working in the banking industry and sometimes also facing great pressures to behave unethically.

\section{OPPORTUNITIES FOR FURTHER RESEARCH}

Although the research has identified factors in the banking industry that influence the behavior of employees and although it has sought to identify the frameworks of preventions applied in the banking industry, a lot more research is necessary to understand all the mechanics of those forces and formulate a clear and definite framework that take these into account to curb unethical behaviors, while remaining 
objective. Based on the premise that each industry has its particularities, future research could also be inspired by this study to also identify factors influencing employee behaviors in other industries.

Also, with regards to the banking industry the next step would be to study whether the way the factors identified in this research influence behaviors in the banking industries changes depending on the market form. This would entail measuring these influences in different countries and comparing them. Further research on external factors outside of the companies' sphere of influence should also be done. Such research would imply that the responsibilities of the management of ethics does not rest solely on the companies, rather it would be by nature participative and would require efforts from all stakeholders that are found to influence.

Finally, more research should be conducted in order to understand the sizable gap that exists between ethics and the interest of employees and banks, and propose theories designed to align them.

\section{REFERENCES}

Albu, R.G., Mandru, L., Titus, S. (2020). Impact of Ethics upon Business Success. Vision 2020: Sustainable Economic development, Innovation Management, and Global Growth. University of Brașov, Romania, 203-211

Abdulkareem, M., Zuhaira, M. (2017). The Effect of Religious Beliefs, Participation and Values on Corruption: Survey Evidence from Iraq. International Journal of Advanced Computer Science and Applications, 8(8): 302-305.

Ali, M. \& Azmi, W., (2016) Religion in the Boardroom and its impact on Islamic Bank's Performance, Review of Financial Economics. https://doi.org/10.1016/j.rfe.2016.08.001

Asu, D. Y. (2017). Status of Ownership of State-Owned Enterprises (BUMN) Persero Once Owned By Private Parties. IUS Journal of Law and Justice Studies, 5(2): 178-188.

Chokprajakchat. (2017). Incorporating the Code of Ethics. Journal of Ethics and Strategic Management, 25-33.

Çelikdemir, DZ, \& Tukel, I. (2015). Incorporating Ethics into Strategic Management with Regards to Generation Y's view of Ethics. Procedia - Social and Behavioral Sciences, 207(1): 528-535.

Chokprajakchat, S., Nittaya, S. (2017). Implementation of the code of professional ethics for Thai civil servants. Elsevier BV Bangkok, Thailand, 38(2): 129-135 https://doi.org/10.1016/i.kjss.2016.03.004

Durr, E. (2019). Urban ethics: Towards a research agenda on cities, ethics and normativity. Elsevier Ltd. Munich, Germany, 1-11

Dekerckhove. (2017). The impact of corporate social responsibility on organizational performance. Journal of Ethics Management, pp. 25-45.

Ferrell, OC., Harrison, D., Ferrell, L., Hair, J. (2018). Business ethics, corporate social responsibility, and brand attitudes: An exploratory study. Elsevier Inc. United States of America, 95(1): 491-501 https://doi.org/10.1016/i.jbusres.2018.07.039 
Geeta, M. (2016) Ethical Behavior in Organizations: A Literature Review. Journal of Research in Business and Management, 4(1): 01-06.

Haghighattalaba, S., Chena, A., Yunxiao, F., Reza, M. (2019). Engineering ethics within accident analysis models. Elsevier Ltd. Beijing, China, Isfahan, Iran, 129: 119-125 https://doi.org/10.1016/i.aap.2019.05.013

Hunt, S. D. (2018). The ethics of branding, customer-brand relationships, brandequity strategy, and branding as a societal institution. Elsevier Ltd. United States of America. Management Research Studies Journal, 1(1): 408-416 https://doi.org/10.1016/j.jbusres.2018.07.044

Horng, J., Hsuan, H., Chang-Yen, T. (2019). Learning corporate ethics and social responsibility: Developing an influential curriculum for undergraduate tourism and hospitality students, Elsevier Ltd. Taiwan, Journal of Hospitality, Leisure, Sport and Tourism Education, 24(1): 100-109.

Jamal, AA. (2018). The Role of Business Ethics in Improving the Quality of Job Performance. Journal of Entrepreneurship \& Organization Management, 07 (01).

Nugraha, I., Bagus, S., Wayan, R. (2015). Influence Professionalism, Professional Ethics and Auditor Training on Auditor Performance At a Public Accounting Firm in Bali. E-Journal of Udayana, University Accounting 13(3).

Olmos, L., Bellido, H., \& Román-Aso, JA (2019). The effects of mega-events on perceived corruption. European Journal of Political Economy, 101826.

Ramboarisata, L., Gendron, C. (2019). Beyond moral righteousness: The challenges of non-utilitarian ethics, CSR, and sustainability education. Elsevier Ltd. Canada, The International Journal of Management Education: 1-12 . https://doi.org/10.1016/.jijme.2019.100321

Saitri, P. W. and Ni, N. A. S. (2017). Influence Machiavellian, Ethical Learning and Ethical Attitudes of Accountants and Students, Scientific Journal of Accounting and Business, 2(1) https://doi.org/10.38043/jiab.v2i1.180 